\title{
RARE PECAM1 VARIANTS IN THREE FAMILIES WITH LYMPHEDEMA
}

S. Michelini, B. Amato, S. Kenanoglu, D. Veselenyiova, A. Dautaj, D. Kurti,

M. Baglivo, M. Dundar, J. Krajcovic, G.A.D. Miggiano, B. Aquilanti, G. Matera,

V. Velluti, L. Gagliardi, S.H. Basha, M. Bertelli

Department of Vascular Rehabilitation (SM), San Giovanni Battista Hospital, Rome; Department of Clinical Medicine and Surgery (BA), University Federico II of Naples, Naples; MAGI Euregio (SK,DV,AD,DK,BM), Bolzano, BZ (headquarters), Italy; Department of Medical Genetics (SK,MD), Faculty of Medicine, Erciyes University, Kayseri, Turkey; University of Ss. Cyril and Methodius In Trnava, Department of Biology (DV,JK), Faculty of Natural Sciences, Trnava, Slovakia; MAGIBalkan (AD,DK), Tirana, Albania; Research Center in Human Nutrition (GADM), Sacro Cuore Catholic University, Rome; UOC Clinical Nutrition (AD,BA,GM,VV,LG), Policlinico Universitario Foundation A. Gemelli IRCCS, Rome, Italy; Innovative Informatica Technologies (MB), Hyderabad, India; EBTNA-Lab, Rovereto (MB), TN; MAGI's Lab, Rovereto, TN, Italy

\section{ABSTRACT}

PECAM1 is a member of the immunoglobulin superfamily and is expressed in monocytes, neutrophils, macrophages and other types of immune cells as well as in endothelial cells. PECAM1 function is crucial for the development and maturation of $B$ lymphocytes. The aim of this study was to link rare PECAM1 variants found in lymphedema patients with the development of lymphatic system malformations. Using NGS, we previously tested 246 Italian lymphedema patients for variants in 29 lymphedema-associated genes and obtained 235 negative results. We then tested these patients for variants in the PECAM1 gene. We found three probands with rare variants in PECAM1. All variants were heterozygous missense variants. In Family 1, the unaffected mother and brother of the proband were found to carry the same variant as the proband. Lymphoscintigraphy was performed to determine possible lymphatic malformations and showed that in both cases a bilateral slight reduction in the speed and lymphatic clearance of the lower limbs. PECAM1 function is important for lymphatic vasculature formation. We found variants in
PECAM1 that may be associated with susceptibility to lymphedema.

Keywords: PECAM1, NGS, genetic diagnostics, lymphedema

PECAM1 (Platelet Endothelial Cell Adhesion Molecule-1) or CD31, is a member of the immunoglobulin superfamily and plays a role in embryogenesis and development (1). The gene encoding PECAM1 is on chromosome 17 (17q23.3) (2) and is composed of 16 exons. The PECAM1 gene is predominantly expressed in platelets, leukocytes and endothelial intercellular junctions $(3,4)$. PECAM1 is also expressed intensively in monocytes, neutrophils, macrophages and other types of immune cells (3). Early studies found high PECAM1 mRNA levels in organs such as lungs, kidneys and heart, and to a lesser extent also in brain and liver (5). Platelet Endothelial Cell Adhesion Molecule-1 has intracellular and extracellular regions. The cytosolic part of the protein is 118 amino acids long and contains serine, tyrosine and threonine residues, which serve as docking sites for various signaling molecules. The extracellular part of PECAM1 is composed of six immunoglobulin-like 
domains, linked to the cytosolic regions by a short transmembrane domain $(3,6)$.

PECAM1 is structurally similar to other intercellular adhesion molecules, such as ICAM-1 (Intercellular Adhesion Molecule 1), VCAM-1 (Vascular Cell Adhesion Molecule 1) and N-CAM (Neural Cell Adhesion Molecule). It takes part in the interactions of activated leukocytes which pass from tissues to lymphatic vessels through the lymphatic endothelium (7). It also takes part the formation of a specialized endothelial junctional mechanosensory complex, comprising itself, VE-cadherin and VEGFR receptors, whose main function relates to sensing blood and lymph flow to regulate vascular remodeling (8-10). Early studies showed the importance of PECAM1 for capillary tube formation, and it was suspected that PECAM1 may be related to the formation of lymphatic vessels as well as blood vessels (11).

The biological functions of PECAM1 depend on the type of cell in which the gene is expressed. In human immune cells, PECAM1 is highly expressed in B cells and CD8+ cells, the latter a type of $T$ cell. However, high levels of PECAM1 are only found in native cells, and PECAM1 is downregulated in B cells and CD8+ cells at maturation. PECAM1 is involved in remodeling of lymphatic vessels during organogenesis. In mice, Pecam-1 deletion results in impaired lymphatic vessel remodeling including abnormal valve morphogenesis (12). Murine Pecam1 is expressed across different $\mathrm{T}$ cell types, $\mathrm{B} 1$ and $\mathrm{B} 2$ cells and also in lymphatic cells in the spleen (3). Studies on mice and cell lines showed that normal Pecam1/CD31 function is important for normal development and maturation of $B$ lymphocytes (B cells). Pecam1/CD31-deficient $B$ cells are overly responsive to calcium and show increased proliferation (13). The phenotype of Pecam 1-- mice includes dysregulated $B$ cells and suggests a role of Pecam1/CD31 as a B-cell coreceptor. Pecam1null mice show abnormal B-cell maturation and elevated antibody response to antigens. Pecam $^{-/-}$mice also spontaneously develop antibodies, which suggests that knockout leads to an alteration of the B lymphocyte with consequent production of autoantibodies. This could be involved in the development of autoimmune diseases (13) (Table 1).

The importance of $B$ cells in the immune and lymphatic system has also been shown in a mouse model. It has been reported that $B$ cells positively affect lymphangiogenesis by expressing vascular endothelial growth factor A (VEGFA) in lymph nodes (14). B cells have also been linked to the development of lymphnode hypertrophy after immunization, namely swollen lymph nodes and a significantly higher B-cell count than in wild-type animals. To prove that $B$ cells are responsible for lymph node hyperplasia, a mouse model lacking B cells was used. The results showed that after immunization, the lymph nodes were slightly enlarged but the increase was significantly less than in mice with normal $B$ cells. These results suggest that $B$ cells play a role in the lymphangiogenesis of lymph nodes and in lymphnode hyperplasia (15). This suggestion has

\section{TABLE 1}

Mouse Model and its Phenotypes Associated with the PecamI gene.

\begin{tabular}{|l|l|l|l|l|}
\hline Organism & Gene & Function & Lethality & Lymphatic phenotypes \\
\hline Mouse & Pecam1 & $\begin{array}{l}\text { Protein } \\
\text { coding }\end{array}$ & viable & $\begin{array}{l}\text { Pecam1 } \\
\text { B- cell maturation and elevated antibody } \\
\text { response to antigens (13), lymph } \\
\text { node hypertrophy (14). }\end{array}$ \\
\hline
\end{tabular}


been confirmed by other experiments, for instance when mice were injected with $\mathrm{CpG}$, a strong $B$ cell activator, they also showed excessive lymphangiogenesis within the lymph nodes (16). This phenotype is also evident in diseases such as lymphedema.

Lymphedema is a chronic disease defined by the accumulation of protein-rich fluid. Clinical manifestations include swelling and an increase in tissue thickness due to fibrosis (17). These tissue changes are caused by poor drainage of protein-rich fluid by the lymphatic system or because lymphatic flow is blocked. The normal development and function of lymphatic capillaries, vessels and lymph nodes is therefore crucial for the prevention of lymphedema. Many different genes have been included in the genetic testing of lymphedema (18). To our knowledge, a direct connection between PECAM1 and lymphedema has not yet been demonstrated, although various authors have linked a phenotype similar to that of lymphedema to a deficiency of PECAM1 ligands $(19,20)$.

Variants in the human PECAM1 primary nucleotide sequence have long been known although their association with pathological phenotypes remains unclear in many cases. PECAM1 is not listed with any human phenotype in OMIM. Some studies have shown an association of PECAM1 missense variants with graft-versus-host disease (21), which features inflammation of different organs and apoptosis of endothelial cells (22).

Substitutions of leucine 96 with valine, serine 536 with asparagine or arginine 643 with glycine are reportedly associated with increased susceptibility to acute graft-versushost disease (23-26). Atherosclerosis and cardiovascular disease are other pathologic conditions linked to variants in PECAM1 (21). Fang et al showed that substitution of leucine 125 with valine is associated with coronary artery disease and suggested a role of PECAM1 in atherosclerosis (27). These observations confirm the complex role of PECAM1 in inflammation and vascular biology and its importance in the development of diseases.

The aim of our study was to investigate the genotype of Italian lymphedema patients with regard to PECAM1, in order to determine whether PECAM1 should be included in panels of genes tested in cases of lymphedema.

\section{MATERIALS AND METHODS}

\section{Clinical Evaluation}

Caucasian patients $(n=246)$ diagnosed with lymphedema in different hospitals across Italy were enrolled retrospectively in the study. No consanguinity was reported in their families. Clinical diagnosis of lymphedema was based on accepted criteria and confirmed by three-phase lymphoscintigraphy according to the protocol of Bourgeois. Lymphoscintigraphy was also performed in the mother and brother of the proband of Family 1. Genetic testing was performed on germline DNA extracted from saliva or blood of probands. Segregation analysis was performed using DNA extracted from saliva of probands' relatives.

\section{Genetic Analysis}

A custom-made oligonucleotide probe library was designed to capture all coding exons and flanking exon/intron boundaries ( $\pm 15 \mathrm{bp}$ ) of 29 genes known to be associated with lymphedema. We added the candidate gene PECAM1 to our panel.

DNA from probands was analyzed. Genetic variants of possible clinical significance (pathogenic, likely pathogenic and of unknown significance according to ACMG guidelines) were confirmed by bidirectional Sanger sequencing on a CEQ8800 Sequencer (Beckman Coulter). Segregation in available family members was performed by Sanger sequencing for variants identified in probands harboring heterozygous variants in PECAM1. We searched the following international databases for all nucleotide changes: dbSNP (www.ncbi.nlm.nih.gov/SNP/) and Human Gene Mutation Database professional (HGMD; http://www.biobase-international.com/product/hgmd). In silico evaluation of 
the pathogenicity of nucleotide changes in exons was performed using the Variant Effect Predictor tool (http://www.ensembl.org/ Tools/ VEP) and MutationTaster (http://www. mutationtaster.org). Minor allele frequencies were checked in the Genome Aggregation Database (GnomAD) (http://gnomad.broadinstitute.org/). All variants were evaluated according to American College of Medical Genetics and Genomics guidelines (28). Detailed pre-test genetic counseling was provided to all subjects, who were then invited to sign specific informed consent to use of their anonymized genetic results for research.

\section{In Silico Analysis}

The primary amino acid sequence of PECAM1 in FASTA format (Table 2) was used as target to search the Swiss model template library (SMTL) version 2019-10-24 and Protein Data Bank (PDB) release 2019-10-18 14 for matching evolution-related structures by means of BLAST (Basic Local Alignment Search Tool) 15 and HHBlits 16. Models were based on target-template alignment using ProMod3 of the SWISSMODEL server (29). Coordinates conserved between the target and the template were copied from the template to the model. Insertions and deletions were remodeled using a fragment library. Side chains were then rebuilt. Finally, the geometry of the resulting model was regularized by the CHARMM27 force field (30). If case loop modelling with ProMod3 failed, an alternative model was built with PROMOD-II (31). Global and per-residue model quality was assessed using the QMEAN scoring function (32). BioVia Discovery Studio Visualizer ver17.2 (33) was used to visualize the modeled protein, to vary the targeted amino acids and to analyze interactions at molecular level.

\section{RESULTS}

\section{Clinical and Genetic Evaluations}

We collected and analyzed samples from 235 lymphedema patients, previously resulted negative for known genes associated to lymphedema. PECAM1 (OMIM 173445) was a possible candidate gene that we tested in the genotype of our probands. We found rare PECAM1 variants in three probands. All cases were sporadic, non-familial, and all three variants were heterozygous. Clinical features are listed in Table 3.

In the first family, we tested the proband and three family members. The proband, a $\mathbf{1 0}$ year- old girl, has lymphedema of the lower limbs, diagnosed when she was 4 months old.

\section{TABLE 2}

Primary Amino Acid Sequence for Which Templates were Searched and Models were Built

MQPRWAQGATMWLGVLLTLLLCSSLEGQENSFTINSVDMKSLPDWTVQNGKNLTLQCFAD VSTTSHVKPQHQMLFYKDDVLFYNISSMKSTESYFIPEVRIYDSGTYKCTVIVNNKEKTTAE YQVLVEGVPSPRVTLDKKEAIQGGIVRVNCSVPEEKAPIHFTIEKLELNEKMVKLKREKNSR DQNFVILEFPVEEQDRVLSFRCQARIISGIHMQTSESTKSELVTVTESFSTPKFHISPTGMIME GAQLHIKCTIQVTHLAQEFPEIIIQKDKAIVAHNRHGNKAVYSVMAMVEHSGNYTCKVESSR ISK VSSIVVNITELFSKPELESSFTHLDQGERLNLSCSIPGAPPANFTIQKEDTIVSQTQDFTKIA SKSDSGTYICTAGIDKVVKKSNTVQIVVCEMLSQPRISYDAQFEVIKGQTIEVRCESISGTLPIS YQLLKTSKVLENSTKNSNDPAVFKDNPTEDVEYQCVADNCHSHAKMLSEVLRVKVIAPVDE VQISILSSKVVESGEDIVLQCAVNEGSGPITYKFYREKEGKPFYQMTSNATQAFWTKQKASK EQEGEYYCTAFNRANHASSVPRSKILTVRVILAPWKKGLIAVVIIGVIIALLIIAAKCYFLRKA KAKQMPVEMSRPAVPLLNSNNEKMSDPNMEANSHYGHNDDVRNHAMKPINDNKEPLNSD VQYTEVQVSSAESHKDLGKKDTETVYSEVRKAVPDAVESRYSRTEGSLDGT 
TABLE 3

Clinical Features of Probands with Rare PECAMI Variants

\begin{tabular}{|c|c|c|c|c|c|c|c|}
\hline Family & Pedigree & Sex & Age & $\begin{array}{l}\text { Clinical } \\
\text { features }\end{array}$ & Age of onset & Familial & Variant nomenclature \\
\hline 1 & Proband & $\mathbf{F}$ & 10 & $\begin{array}{l}\text { Lower } \\
\text { limb } \\
\text { lymph- } \\
\text { edema }\end{array}$ & $\begin{array}{c}4 \\
\text { months }\end{array}$ & NO & $\begin{array}{l}\text { NM_000442.4:c.1928C>T/wt; } \\
\text { NP_000433.4:p.Pro643Leu }\end{array}$ \\
\hline 1 & Father & $\mathbf{M}$ & 42 & healthy & I & NO & wt/wt \\
\hline 1 & Mother & $\mathbf{F}$ & 40 & healthy & I & NO & $\begin{array}{l}\text { NM_000442.4:c.1928C>T/wt; } \\
\text { NP_000433.4:p.Pro643Leu }\end{array}$ \\
\hline 1 & Brother & M & 13 & healthy & I & NO & $\begin{array}{l}\text { NM_000442.4:c.1928C>T/wt; } \\
\text { NP_000433.4:p.Pro643Leu }\end{array}$ \\
\hline 2 & Proband & F & 68 & $\begin{array}{l}\text { Foot } \\
\text { lymph- } \\
\text { edema }\end{array}$ & 12 & NO & $\begin{array}{l}\text { NM_000442.4:c.1928C>T/wt; } \\
\text { NP_000433.4:p.Pro643Leu }\end{array}$ \\
\hline 3 & Proband & $F$ & 68 & $\begin{array}{l}\text { Lower } \\
\text { limb } \\
\text { lymph- } \\
\text { edema }\end{array}$ & $\begin{array}{c}\text { In } \\
\text { adolescence }\end{array}$ & NO & $\begin{array}{l}\text { NM_000442.4:c.208C > T/wt; } \\
\text { NP_000433.4:p.Gln70Ter }\end{array}$ \\
\hline
\end{tabular}

She was found to carry a rare, heterozygous, single nucleotide variant NM_000442.4: c. $1928 \mathrm{C}>\mathrm{T}$. This variant causes an amino acid change from proline to leucine in position 643. SIFT and PolyPhen assessed this variant as deleterious and possibly damaging (0.999), respectively. The missense variant is listed in dbSNP as rs45552934; according to GnomAD, allele frequency is $\mathbf{0 . 0 0 2 3 8 3}$. The mother and brother of the proband carried the same variant as the proband (Fig. 1), although neither has lymphedema. To determine possible lymphatic system malformations, lymphoscintigraphy was performed. In the mother and brother, lymphatic scintigraphy (tracker: 99m-Tc-nanocolloidal, at dose: 22 $\mathrm{mCi}-74 \mathrm{MBq}$, by intradermal infiltration of radionuclides into the interdigital spaces of both feet, followed by serial reliefs of colloid) was performed.

1) In the dynamic phase, good lymphatic progression is appreciated in both legs but the appearance of lymph nodes at 60 minutes, bilaterally, is compatible with a modest reduction in lymphatic velocity for both ( $>1<2 \mathrm{~cm} / \mathrm{min}$.);

2) The whole body images at $120 \mathrm{~min}$. (stress phase) demonstrate: bilaterally complete visualization of the lymphatic axis and the inguinal, crural, iliac and aortic drainage lymph nodes in the absence of images of lymphatic accumulation / back-flow but clearance of interdigital sites (corrected for decay and attenuation - geometric mean method) is bilaterally decreased ( $27 \%$ for the mother and $25 \%$ for the brother).

The second proband with a PECAM1 variant is a 68 year-old female, affected with lymphedema of the foot, diagnosed at age 12 years. The proband carries the same variant as the first proband, a single missense nucleotide variant NM_000442.4:c.1928C > T. 


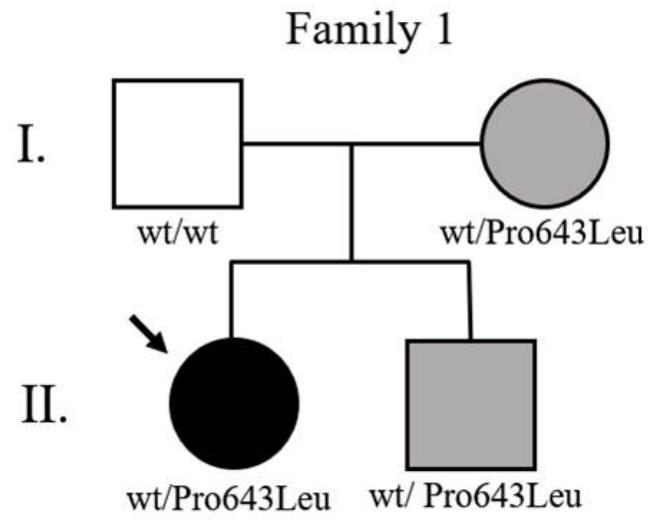

clinical symptoms

$\square$ sub-clinical symptoms

$\square$ unaffected

$\longrightarrow$ proband

Fig 1. Pedigree of Family 1 for PECAM1 gene. Proband is $a$ girl with primary lymphedema and $a$ heterozygous missense variant in PECAM1. The same variant was identified in the proband's mother and brother who have subclinical findings.

The third proband found to carry a rare PECAM1 variant is a 68 year-old female with lymphedema of the lower limbs; age of onset in her youth. In this case, we identified a heterozygous nonsense variant, NM_000442.4: c. $208 \mathrm{C}>\mathrm{T}$. This variant causes a stop gain, changing glutamine 70 to a stop codon, resul- ting in a truncated protein. This variant is not listed in the dbSNP database and its frequency is unknown. Details of the PECAM1 variants are summarized in Table 4.

\section{In Silico Analysis, Template Selection and Model Building}

Template search with BLAST and HHBlits was performed against the SWISSMODEL template library (SMTL, last update: 2019-10-24, last included PDB release:

2019-10-18). The target sequence was searched with BLAST against the primary amino acid sequence in the SMTL. A total of 8162 matching templates were found with various sequence identity and quality percentages. Details of the top ten templates are shown in Table 5.

Based on the percentage of sequence identity, similarity and best quality square, the 6GRT.1.A chain was selected to align the template and query sequences towards model building. The model is shown in Fig. 2. We then entered the built model in Discovery studio visualizer to generate Pro643Leu mutant versions of the model structure. Molecular level interaction analysis between native/mutant residues produced the snapshots shown in Fig. 3. Details of the residues involved in interactions, the types of bond they formed and bond lengths in angstrom units are shown in Table 6.

\section{DISCUSSION}

\begin{tabular}{|c|c|c|c|c|}
\hline \multicolumn{5}{|c|}{$\begin{array}{c}\text { TABLE } 4 \\
\text { The Two Rare PECAMI Variants }\end{array}$} \\
\hline Variant & dbSNPid & Sift & PolyPhen & $\begin{array}{r}\text { Frequency } \\
\text { (GnomAD) }\end{array}$ \\
\hline $\begin{array}{l}\text { PECAM1:NM_000442.4:c.1928 } \\
\text { C>T:NP_000433.4:p.Pro643Leu }\end{array}$ & rs45552934 & deleterious & $\begin{array}{c}\text { Possibly } \\
\text { damaging }\end{array}$ & 0.002383 \\
\hline $\begin{array}{l}\text { PECAM1:NM_000442.4:c.208C } \\
\text { >T:NP_000433.4:p.Gln70Ter }\end{array}$ & I & I & I & I \\
\hline
\end{tabular}




\begin{tabular}{|c|c|c|c|c|c|c|c|c|c|}
\hline \multicolumn{10}{|c|}{ TABLE 5} \\
\hline Template & $\begin{array}{r}\text { Sequence } \\
\text { Identity }\end{array}$ & $\begin{array}{l}\text { Oligo- } \\
\text { state }\end{array}$ & $\begin{array}{l}\text { QS } \\
\text { QE }\end{array}$ & $\begin{array}{l}\text { Found } \\
\text { by }\end{array}$ & Method & $\begin{array}{c}\text { Resolu- } \\
\text { tion }\end{array}$ & $\begin{array}{l}\text { Sequence } \\
\text { similarity }\end{array}$ & $\begin{array}{l}\text { Cover- } \\
\text { age }\end{array}$ & Description \\
\hline 6grt.1.A & 16.21 & $\begin{array}{l}\text { Mono- } \\
\text { mer }\end{array}$ & - & HHblits & X-ray & $4.50 \AA$ & 0.29 & 0.74 & $\begin{array}{c}\text { Paired immunoglobulin-like } \\
\text { receptor B }\end{array}$ \\
\hline 6grt.2.A & 16.21 & $\begin{array}{l}\text { Mono- } \\
\text { mer }\end{array}$ & - & HHblits & X-ray & $4.50 \AA$ & 0.29 & 0.74 & $\begin{array}{c}\text { Paired immunoglobulin-like } \\
\text { receptor B }\end{array}$ \\
\hline 6grs.1.B & 16.21 & $\begin{array}{l}\text { homo- } \\
\text { dimer }\end{array}$ & 0.11 & HHblits & X-ray & $3.40 \AA$ & 0.29 & 0.74 & $\begin{array}{l}\text { Paired immunoglobulin-like } \\
\text { receptor B }\end{array}$ \\
\hline 6grs.1.A & 16.21 & $\begin{array}{l}\text { homo- } \\
\text { dimer }\end{array}$ & 0.10 & HHblits & X-ray & $3.40 \AA$ & 0.29 & 0.74 & $\begin{array}{l}\text { Paired immunoglobulin-like } \\
\text { receptor B }\end{array}$ \\
\hline 3dmk.2.A & 16.23 & $\begin{array}{l}\text { homo- } \\
\text { dimer }\end{array}$ & 0.08 & HHblits & X-ray & $4.19 \AA$ & 0.29 & 0.72 & \begin{tabular}{|c|} 
Down Syndrome Cell \\
Adhesion Molecule \\
(DSCAM) isoform 1.30.30, \\
N-terminal eight Ig domains \\
\end{tabular} \\
\hline 3dmk.1.B & 16.23 & $\begin{array}{l}\text { homo- } \\
\text { dimer }\end{array}$ & 0.08 & HHblits & X-ray & $4.19 \AA ̊$ & 0.29 & 0.72 & $\begin{array}{c}\text { Down Syndrome Cell } \\
\text { Adhesion Molecule } \\
\text { (DSCAM) isoform 1.30.30, } \\
\text { N-terminal eight Ig domains }\end{array}$ \\
\hline 3dmk.1.A & 16.23 & $\begin{array}{l}\text { homo- } \\
\text { dimer }\end{array}$ & 0.08 & HHblits & X-ray & $4.19 \AA ̊$ & 0.29 & 0.72 & \begin{tabular}{|c|} 
Down Syndrome Cell \\
Adhesion Molecule \\
(DSCAM) isoform 1.30.30, \\
N-terminal eight Ig domains \\
\end{tabular} \\
\hline 5oj2.2.A & 16.86 & $\begin{array}{l}\text { Mono- } \\
\text { mer }\end{array}$ & - & HHblits & X-ray & $3.20 \AA$ & 0.29 & 0.72 & $\begin{array}{c}\text { MAM domain-containing } \\
\text { glycosylphosphatidylinositol } \\
\text { anchor protein } 1\end{array}$ \\
\hline 5oj6.1.D & 16.86 & $\begin{array}{l}\text { Mono- } \\
\text { mer }\end{array}$ & - & HHblits & X-ray & $3.30 \AA ̊$ & 0.29 & 0.72 & $\begin{array}{c}\text { MAM domain-containing } \\
\text { glycosylphosphatidylinositol } \\
\text { anchor protein } 1\end{array}$ \\
\hline 5oj2.1.A & 16.86 & $\begin{array}{l}\text { Mono- } \\
\text { mer }\end{array}$ & - & HHblits & X-ray & $3.20 \AA$ & 0.29 & 0.72 & $\begin{array}{c}\text { MAM domain-containing } \\
\text { glycosylphosphatidylinositol } \\
\text { anchor protein } 1\end{array}$ \\
\hline
\end{tabular}

Lymphedema can be a devastating disease, both physically and psychologically. A panel of known lymphedema genes is used for genetic testing of lymphedema patients and their families (18). We used this panel on a cohort of 246 Italian lymphedema patients and found that 235 of these probands tested negative. We therefore performed additional testing for new candidate genes, including $P E C A M 1$, described in this paper.

We identified PECAM1 variants in three out of 235 patients $(3 / 235 ; 1.27 \%)$. The three probands show similar clinical features: they are all female and have lymphedema of the lower limbs or parts thereof. Age of onset was childhood in all three and all three were sporadic cases. All variants were heterozygous and two probands had the same variant. In the case of the first proband, a 10 year-old girl, both parents and an older brother were also tested. Mother and brother carry the same heterozygous missense variant as the proband but they have not developed lymphedema. However, their lymphoscintigraphy results 

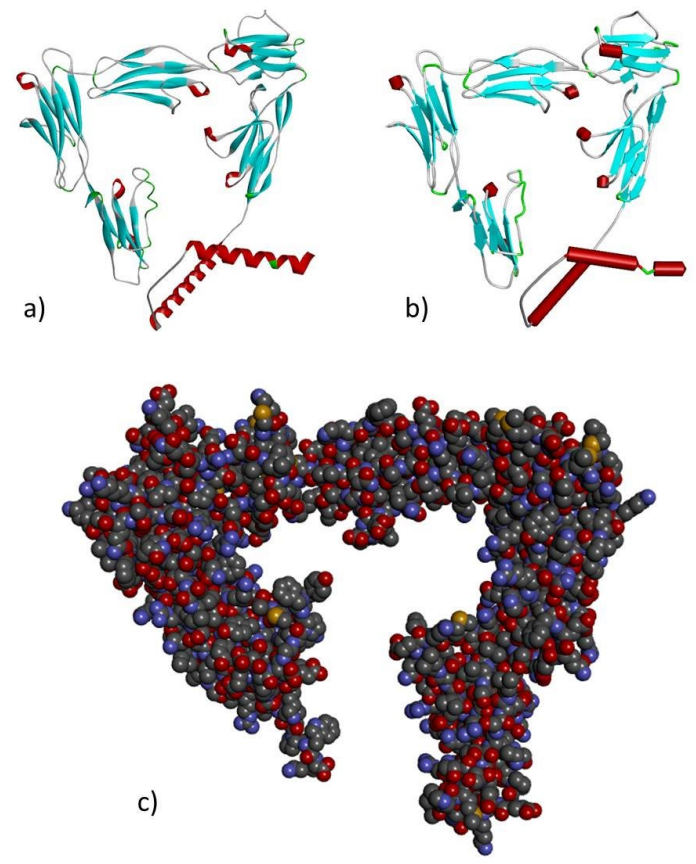

Fig. 2. Modelled structure of PECAM1 (Platelet Endothelial Cell Adhesion Molecule-1) in a) ribbon b) schematic and c) CPK view. Cyan regions represent beta sheets white regions represent loops and red regions represent alpha helices. CPK view: carbon is indicated in grey, oxygen in red, nitrogen in blue, hydrogen in white, chlorine in green, sulfur in yellow, phosphorus in orange and iron in reddish brown. showed that lymphatic drainage of the limbs was impaired, compatible with grade 0 lymphedema (lymphatic changes in the absence of evident clinical signs of lymphedema). The second proband, a 68 year-old woman, carries the same variant as the first proband; no family members of this proband were tested. The third proband is another 68 year-old woman with a stop-gain variant not listed in dbSNP. No family members of this proband were tested.

To understand the significance of alterations due to PECAM1 variants, we conducted bioinformatic analysis.In silico analysis showed that the PECAM1 gene structure with Pro643 has major differences in stability with respect to the mutant structure with Leu643 in terms of direct hydrogen bonding with nearby Pro640. The said hydrogen bond was $\mathbf{2 . 1 0}$ Angstroms in length, which is considered to be strong and to have high impact in stabilizing the structure whereas the mutant Leu643 does not form a direct hydrogen bond with nearby Pro640 but a weak hydrophobic interaction having a bond length of 4.58 Angstroms. This is evidence that the overall protein conformation is altered by these different interactions, causing functional defects in the protein.

Although PECAM1 has never been explicitly
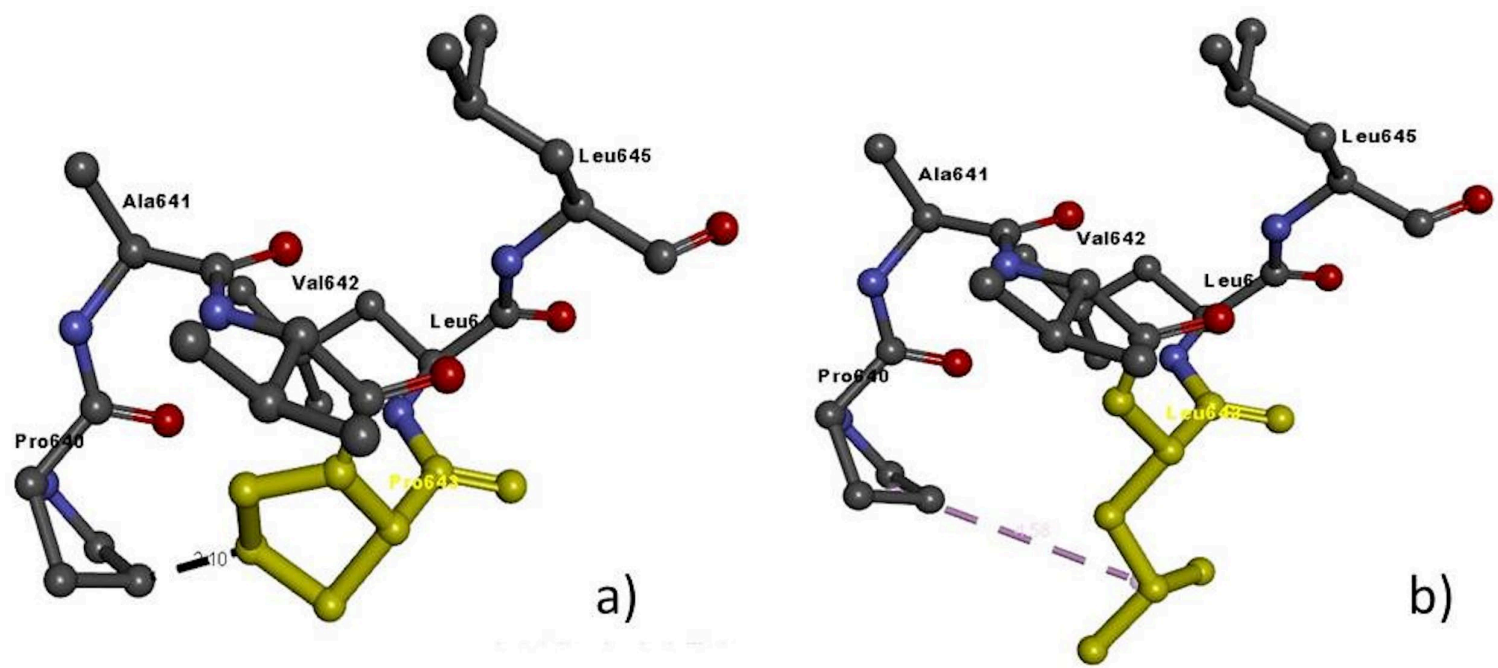

Fig. 3. Showing molecular interactions of a) Pro643 and b) Leu643 (in yellow) of the PECAM1 protein model with adjacent interacting residues. 


\begin{tabular}{|c|c|c|c|c|c|}
\hline \multicolumn{6}{|c|}{$\begin{array}{l}\text { Table 6: Details of Molecular Interactions of a) Pro643 and b) Leu643 of the } \\
\text { PECAM1 Protein Model with Adjacent Interacting Residues }\end{array}$} \\
\hline S.No & Mutation & Amino acid & $\begin{array}{c}\text { Molecular } \\
\text { interactions } \\
\text { observed }\end{array}$ & $\begin{array}{c}\text { Bond } \\
\text { length in } \\
\text { Angstroms } \\
\end{array}$ & Bond type \\
\hline 1. & Pro643Leu & Pro643 & $\begin{array}{l}\text { Pro640:C - } \\
\text { Pro643:C }\end{array}$ & 2.10 & H-bond \\
\hline 2. & & Leu643 & Pro640 - Leu643 & 4.58 & Hydrophobi \\
\hline
\end{tabular}

linked to the development of lymphedema, data from the scientific literature demonstrates a close connection between PECAM1 and lymphatics. PECAM1 is involved in the development of lymphatic vessels. Interestingly, knockout mice in this gene, during their organogenesis, develop malformation of lymphatic vessels from the 18th week. In addition, Pecam1 knockout mice also develop severe edema (12). Notably, PECAM1 is expressed in lymphatic vessels and in endothelial intercellular junctions, and is necessary for migration of immune cells $(6,34)$. PECAM null mice exhibit defects of both lymphatic vessel and valves structures, suggesting a potential direct contribution of endothelial flow sensing dysfunction in lymphedema development (12). It is also expressed at high levels in B lymphocytes, which are important for normal immune system function. Pecam1/CD31 is reported to be important for appropriate proliferation of $B$ cells in mice, where its knockout leads to B-cell over-proliferation and failed maturation (13). Furthermore, studies with Pecam1-null mice also suggest that Pecam1/CD31 has a role in autoimmune diseases since B cells spontaneously developed antibodies and showed an excessive antibody response to antigen presentation in knockout animals (13). Overproliferation of $B$ cells has been shown to cause lymphangiogenesis and hyperplasia of lymph nodes in a mouse model $(15,16)$. Hyperplasia of lymph nodes also occurs in some lymphedema patients. Liu et al (2012) found hyperplasia of lymph nodes in $28 \%$ of 378 lymphedema cases $(35,36)$. Moreover, excessive lymphangiogenesis is often seen in lymphedema patients, where it may be related to obstruction of lymph flow and subsequent edema and inflammation. Dysregulation of PECAM1 is also linked, for example, to inflammatory diseases (21), susceptibility to malaria (37), atherosclerosis/ cardiovascular disease (27) and cancer (38-40).

To the best of our knowledge, PECAM1 polymorphisms have never been associated with lymphedema in humans. However, our results suggest that PECAM1 could play a role in predisposition to lymphedema. Our hypothesis is supported by the co-segregation of the variant with lymphedema phenotypes.

PECAM1 should therefore be considered a candidate gene to include in panels for genetic testing of lymphedema patients.

\section{ACKNOWLEDGMENTS}

We would like to thank Prof. Nicolas Baeyens for his support in the contents of the manuscript. We thank Helen Ampt for English language editing. This work was supported by funding from the Provincia Autonoma di Trento within the initiative LP 6/99 (dgp 1045/2017).

\section{CONFLICT OF INTEREST AND DISCLOSURE}

The authors declare no competing 
financial interests exist.

\section{REFERENCES}

1. Baluk, P, J Fuxe, H Hashizume, et al: Functionally specialized junctions between endothelial cells of lymphatic vessels. J. Exp. Med. 204 (2007), 2349-2362. doi:10.1084/jem. 20062596

2. Gumina, RJ, NE Kirschbaum, PN Rao, P VanTuinen, PJ Newman: The Human PECAM1 Gene Maps to 17q23. Genomics 34(1996), 229-232. doi:10.1006/geno. 1996.0272

3. Jackson, DE: The unfolding tale of PECAM1. FEBS Lett. 540 (2003) 7-14. doi:10.1016/S0014-5793(03)00224-2

4. Privratsky, JR, PJ Newman: PECAM-1: Regulator of endothelial junctional integrity. Cell Tissue Res. 355 (2014), 607-619. doi:10.1007/s00441-013-1779-3

5. Sheibani, N, CM Sorenson, WA Frazier: Tissue specific expression of alternatively spliced murine PECAM-1 isoforms. Dev. Dyn. 214 (1999), 44-54. doi:10.1002/ (SICI)1097-0177(199901)214:1<44::AIDDVDY5>3.0.CO;2-L

6. Newman, PJ, MC Berndt, J Gorski, et al: Molecules of the immunoglobulin gene superfamily. Cell. 23 (1990), 1219.

7. Vaporciyan, A, H DeLisser, $\mathrm{H}$ Yan, et al: Involvement of platelet-endothelial cell adhesion molecule-1 in neutrophil recruitment in vivo. Science 262 (1993) 15801582. doi:10.1126/science. 8248808

8. Tzima, E, M Irani-Tehrani, WB Kiosses, et al: A mechanosensory complex that mediates the endothelial cell response to fluid shear stress. Nature 437 (2005), 426-431. doi:10.1038/nature03952

9. Coon, BG, N Baeyens, J Han, et al: $\square$ Intramembrane binding of VE-cadherin to $\square$ VEGFR2 and VEGFR3 assembles the $\square$ endothelial mechanosensory complex. J. Cell. $\square$ Biol. 208 (2015), 975-986. doi:10.1083/ jcb.201408103

10. Baeyens, N, S Nicoli, BG Coon, et al: Vascular remodeling is governed by $\mathrm{a} \square$ VEGFR3-dependent fluid shear stress set! point. Elife 2015;4:e4642015:1-16. doi:10.7554/eLife. 04645

11. Sawa, Y, S Yoshida, Y Ashikaga, T Kim, Y Yamaoka, H Shiroto: Lymphatic endothelium $\square$ expresses PECAM-1. Tissue Cell. 30 (1998), Шा1382. doi:10.1016/S0040-8166(98)80051-7
12. Wang, $\mathrm{Y}, \mathrm{N}$ Baeyens, F Corti, et al: Syndecan-4 controls lymphatic vasculature remodeling during embryonic development. Development 143 (2016), 4441-4451. doi:10.1242/dev.140129

13. Wilkinson, R, A Bruce Lyons, D Roberts, MX Wong, PA Bartley, DE Jackson: Platelet endothelial cell adhesion molecule-1 (PECAM-1/CD31) acts as a regulator of B-cell development, B-cell antigen receptor (BCR)-mediated activation, and autoimmune disease. Blood 100 (2002), 184-193. doi:10.1182/blood-2002-01-0027

14. Liao, S, PY von der Weid: Lymphatic system: An active pathway for immune protection. Semin. Cell Dev. Biol. 38 (2015), 83-89. doi:10.1016/j.semcdb.2014.11.012

15. Angeli, V, F Ginhoux, J Llodrà, et al: $B$ celldriven lymphangiogenesis in inflamed lymph nodes enhances dendritic cell mobilization. Immunity 24 (2006), 203-215. doi:10.1016/ immuni.2006.01.003

16. Krieg, AM: CpG Motifs in bacterial DNA and their immune effects. Annu. Rev. Immunol. 20 (2002), 709-760. doi:10.1146/ annurev.immunol.20.100301.064842 Michelini,

17. $\mathrm{S}, \mathrm{M}$ Cardone, $\mathrm{P}$ Maltese, A Bruson, $\mathrm{A}$ Fiorentino, M Bertelli: Primary lymphedema and genetic implications. EuroBiotech J. 1 (2017), 144-146. doi:10.24190/ISSN2564-615X/2017/S2.07

18. Michelini, S, S Paolacci, E Manara, et al: Genetic tests in lymphatic vascular malformations and lymphedema. J. Med. Genet. 55 (2018), 222-232. doi:10.1136/jmedgenet-2017-105064

19. Baluk, P, T Tammela, E Ator, et al: Pathogenesis of persistent lymphatic vessel hyperplasia in chronic airway inflammation. Clin. Invest. 115 (2005), 247-257. doi:10.1172/JCI200522037

20. Johnson, LA, S Clasper, AP Holt, PF Lalor, D Baban, DG Jackson: An inflammationinduced mechanism for leukocyte transmigration across lymphatic vessel endothelium. J. Exp. Med. 203 (2006), 27632777. doi:10.1084/jem.20051759

21. Novinska, MS, BC Pietz, TM Ellis, DK Newman, PJ Newman: The alleles of PECAM-1. Gene 376 (2006), 95-101. doi:10.1016/j.gene.2006.02.016

22. Ferrara, JL, JE Levine, P Reddy, E Holler: Graft-versus-host disease. Lancet. 373 (2009), 1550-1561. doi:10.1016S0140-6736(09) 60237-3

23. Maruya, E, H Saji, S Seki, et al: Evidence that CD31, CD49b, and CD62L are immunodominant minor histocompatibility antigens in 
HLA identical sibling bone marrow transplants. Blood 92 (1998), 2169-2176. doi:10.1182/blood.V92.6.2169

24. Balduini, CL, P Noris, G Giorgiani, et al: Incompatibility for CD31 and human platelet antigens and acute graft- versus-host disease after bone marrow transplantation. Br. J. Haematol. 106 (1999), 723-729. doi:10.1046/j.1365-2141.1999.01585.x

25. Grumet, FC, DD Hiraki, BW Brown, et al: CD31 mismatching affects marrow transplantation outcome. Biol. Blood Marrow Transplant. 7 (2001), 503-512. doi:10.1053/bbmt.2001.v7.pm11669217

26. Cavanagh, G, CE Chapman, V Carter, AM Dickinson, PG Middleton: Donor CD31 genotype impacts on transplant complications after human leukocyte antigen-matched sibling allogeneic bone marrow transplantation. Transplantation 79 (2005), 602-605. doi:10.1097/01.TP.0000153153.94195.87

27. Fang, L, H Wei, SH Chowdhury, et al: Association of Leu125Val polymorphism of platelet endothelial cell adhesion molecule-1 (PECAM-1) gene \& soluble level of PECAM-1 with coronary artery disease in Asian Indians. Indian J. Med. Res. 121 (2005), 92-99.

28. Richards, S, N Aziz, S Bale, et al: Standards and guidelines for the interpretation of sequence variants: A joint consensus recommendation of the American College of Medical Genetics and Genomics and the Association for Molecular Pathology. Genet. Med. 17 (2015), 405-424. doi:10.1038/ gim.2015.30

29. Waterhouse, A, M Bertoni, S Bienert, et al: SWISS-MODEL: Homology modelling of protein structures and complexes. Nucleic Acids Res. 46 (2018), W296-W303. doi:10.1093/nar/gky427

30. Mackerell, AD, M Feig, CL Brooks: Extending the treatment of backbone energetics in protein force fields: Limitations of gas-phase quantum mechanics in reproducing protein conformational distributions in molecular dynamics simulation. J. Comput. Chem. 25 (2004), 1400-1415. doi:10.1002/jcc.20065

31. Guex, N, MC Peitsch, T Schwede: Automated comparative protein structure modeling with SWISS-MODEL and Swiss-PdbViewer: A historical perspective. Electrophoresis 30(SUPPL.1) (2009), 162-173. doi:10.1002/ elps.200900140
32. Benkert, P, M Biasini, T Schwede: Toward the estimation of the absolute quality of individual protein structure models. Bioinformatics 27 (2011), 343-350. doi:10.1093/bioinformatics/btq662

33. Studio BD: Dassault Systèmes BIOVIA. Discovery Studio Modeling Environment [Internet]; 2016.

34. Muller, WA, SA Weigl, X Deng, DM Phillips: PECAM-1 is required for transendothelial migration of leukocytes. J. Exp. Med. 178 (1993), 449-460. doi:10.1084/jem.178.2.449

35. Liu, NF, ZX Yan, XF Wu: Classification of lymphatic-system malformations in primary lymphoedema based on MR lymphangiography. Eur. J. Vasc. Endovasc. Surg. 44 (2012), 345-349. doi:10.1016/j.ejvs.2012. 06.019

36. Liu, N: Truncular Lymphatic Malformation (LM): Primary Lymphedema. In: Congenital Vascular Malformations. Kim, Y-W, B-B Lee, WF Yakes, Y-S Do (Eds.), Berlin, Heidelberg: Springer Berlin Heidelberg, (2017), 121-128. doi:10.1007/978-3-662-46709-1_19

37. Kikuchi, M, S Looareesuwan, $\mathbf{R}$ Ubalee, et al: Association of adhesion molecule PECAM1/CD31 polymorphism with susceptibility to cerebral malaria in Thais. Parasitol. Int. 50 (2001), 235-239. doi:10.1016/S1383-5769(01) 00082-4

38. Terashima, M, W Ichikawa, A Ochiai, et al: TOP2A, GGH, and PECAM1 are associated with hematogenous, lymph node, and peritoneal recurrence in stage II/III gastric cancer patients enrolled in the ACTS-GC study. Oncotarget 8 (2017), 57574-57582.

39. Abraham, V, G Cao, A Parambath, et al: Involvement of TIMP-1 in PECAM-1mediated tumor dissemination. Int. J. Oncol. 53 (2018), 488-502. doi:10.3892/ijo.2018.4422

40. Wai Wong, C, DE Dye, DR Coombe: The role of immunoglobulin superfamily cell adhesion molecules in cancer metastasis. Int. J. Cell Biol. 2012 (2012), 1-9. doi:10.1155/ 2012/340296

\author{
Astrit Dautaj, MD \\ EBTNA-Lab \\ Via delle Maioliche 57 D \\ Rovereto, TN, Italy \\ E-mail: astrit.dautaj@assomagi.org
}

